\title{
Can you Teach Children with That App? Using Mobile Technology to Teach Health Education in Grades 4 and 5
}

\author{
Wahid Khan, Saira Shah \\ OISE \\ University of Toronto
}

\begin{abstract}
The question underpinning this study was 'How do students respond to specific mobile technology applications as tools in teaching health education (HE)?' in order to understand the educational potential for these devices. The goal of this study was twofold: First, it examines the impact of mobile technology in the classroom by observing the use of mobile apps among grade 4/5 students during their lunch period. Secondly, it uses a traditional in class teaching approach to understand how mobile applications may be used to teach HE during instruction time. This paper will report on the first phase examining four different types of health related mobile apps and their effectiveness in the classroom.
\end{abstract}

\section{Introduction}

Mobile technology has modernized learning settings (i.e. recording, taking photos, facilitating note taking) and has been able to reach different learning styles [13]. It is more commonly used in post secondary educational instruction. Studies have shown that mobile technology has increased active student learning participation when students receive content through their mobile phones, promoting social and intellectual interactions as students with PDA's may even outperform their counterparts without PDAs [13] [27]. Ostashewski, Reid and Ostashewski describe how iPads are beneficial in areas such as mobile small group demonstrations, student directed playback-and-practice activities and leading large group demonstrations [20]. Additionally, many studies have tested mobile applications in special education settings to develop social and life skills in children with Autism Spectrum Disorders with implications for students with ADHD [17] [18]. Teacher perceptions have long been infused with belief that handheld mobile devices aide students in achieving higher scores over traditional paper and pencil [26]. Yet, the debate between print-based traditions and new digital literacies continues unabated amongst educators [15].

Existing systematic reviews frequently evaluate mobile health interventions in improving health care delivery processes, and child health [8] [9]. Little research exists on using technology for teaching health education in elementary classrooms. Mobile technology may be used in furthering and promoting health education as children, particularly adolescents have shown enthusiasm for health education through this medium [23]. Much of the larger landscape identifying the effectiveness of specific educational games is scarce and obsolete [16] [19]. More recently, using technology to aid in teaching health education has generated some interest [1] [21]. Baranowski, Buday and Baranowski suggest that role-playing video games aimed at changing physical activity and diet behaviors have positive effects on changing health behaviors [2]. Consolvo, Everitt, Smith and Landay examined mobile applications intended to improve physical activity and found that positive changes in participants arose from social pressure [5].

Students were more motivated to achieve their goals since they were sharing their results with one another. Subsequently, Lin, Mamykina, Lindtner, Delajoux and Strub's study evaluated a computer application reporting that although the novelty of the application wore off after a short period, positive changes in daily routines of physical activity were made among students [14]. Furthermore, while studies that focus on identifying application designs and content features to support or inhibit student learning exist, the research landscape testing specific applications remains scant [6].

\section{Methodology}

\subsection{Participants and Context}

The study took place within a suburban Canadian school district consisting of approximately 80,000 elementary students, transpiring in a single class with grade 4 and grade 5 students of mixed abilities $(\mathrm{N}=28$, 
10 -grade $4 \mathrm{~s}$ and 18-grade $5 \mathrm{~s}$ ). The class has an imbalance of males and females $(\mathrm{N}=28,8$ females and 20 males). The Grade 4's range from 8 years to 9 years and the grade 5's range from 9 years to 10 years. I, the classroom teacher and investigator of this study, have been a teacher in this school for 6 years. Each student joined the classroom at the start of the school year (September, 2012).

\section{Plan of Action}

Each week I presented students with the option of playing a mobile application (app) version of a Health Education (HE) game. Each game was first modeled to the class and students were asked to read the instructions within each app. Only one game was offered each day for one week in total. This allowed daily time to observe, reflect and plan each weekend for the subsequent week of action.

The action research plan occurred each day for four weeks during the 20-minute daily indoor (11:55 a.m-12:15 a.m.) lunch break. I observed and reported on actions that occurred within a 15-minute period from 12:00 pm -12:15 pm allowing time for students to get their lunch and sit down. 12 students stayed at school to eat their lunches in the classroom everyday (6 grade $4 \mathrm{~s}$ and 6 grade $5 \mathrm{~s})$. The students that did not stay $(n=16)$ ate at home and returned during the hour. Those students that stayed at school during lunch were sent outside for a 40-minute lunch recess break following the indoor lunch period.

My action research plan was in harmony with the practical action research approach that asks the researcher/teacher to plan, implement and reflect on the path taken during the teaching process [11].

\section{Description of Applications}

Apple was selected given its dominant force in the educational market over other platforms [3]. The following 4 health related apps were used from the Apple iTunes store under 'health and fitness' within the 'healthy eating' subcategory, and were presented in this order: Green Smoothie Game Lite, Fit Quest Lite, Lose It!, and Green Smoothie Full Version. These apps were initially analyzed and critiqued for their usage in promoting health education, how well they supported the Ontario curriculum, my long range teaching plans in health education, and their popularity and positive ratings on the Apple iOS platform.

Green Smoothie Game Lite aims to educate its users about health education through controlling a squirrel in catching healthy items in an effort to make a healthy "green" smoothie [4].
In Fit Quest Lite, the user controls a squirrel by navigating through a territory while encountering predators. In order to remain alive, the user must engage in physical activity (i.e. jog, hop) to proceed through numerous levels [10].

The third app, Lose It!, asks the user to input their weight, caloric intake and exercise regiment while setting goals and monitoring their daily calories. The app facilitates this with multiple features (i.e. recipes, a food and exercise database) Lose It! is compatible with many exercise apps and wearable bands that record exercise data. It also allows the user to add friends and monitors their progress [7].

The fourth app, Green Smoothie Full Version, offers more levels for the squirrel character (as described in the first application) to proceed through. Upon completion the app unlocks a new character whose intent becomes to recycle waste instead of creating smoothies [4].

\section{Materials}

Classroom mobile devices $(\mathrm{N}=8$ class devices; 2 iPads, 6 iPod Touches) were accessible by all students and required no login or password to use. Student owned mobile devices brought to school for classroom work ( $\mathrm{N}=5$ student owned devices; 1 iPad mini, 4 iPod Touches) were also used.

\section{Data Collection and Analysis Methods}

I engaged in Kemmis and McTarggart's long noted 4 moments: 1) Planning, 2) Action 3) Observation and 4) Reflection once on a weekly basis [11]. Within each phase, I implemented my own ideas of best practice and reflected on them throughout the process (see Figure 1)

\begin{tabular}{|l|l|}
\hline Plan for Phase 1 & \multicolumn{1}{c|}{ Time } \\
\hline Practical Action Research & 1) Planning \\
\hline 4 weeks & 2) Action \\
\hline & 3) Findings \\
\hline & 4) Reflection \\
\hline
\end{tabular}

\section{Figure 1. Action Research Plan for Phase 1}

The data collection was conducted through anecdotal observational notes in which the students' comments, actions, behaviors and reactions were recorded and critically analyzed. I highlighted observations and quotes and then grouped them into emerging themes. Upon completion I sifted through these themes reconsidering, reorganizing and reformulating the emerging ideas. The data was collected as part of my 
personal reflective journaling which I completed daily, an integral component of the action research ethos. Subsequently, my teaching practice was informed and adjusted in order to implement new strategies to improve my HE pedagogical practices. I have attempted to protect student anonymity by using false names for them in this article.

\section{Results and Discussion}

\subsection{Week 1 - Green Smoothie Lite}

The observational period began on the first day (Monday) of a four day week. The Friday at the end of the week was a holiday along with the following Monday, resulting in two consecutive four day weeks. Since this was the first day, the students were caught off guard given that technology devices are generally not used during lunch hour.

As the students began playing Green Smooth Lite, I observed student enjoyment from both grades. Students would say, things like "Yes! or "This is easy!" as their Squirrel character picked up the correct healthy items that fell from the treetop.

By the end of Tuesday (day 2 of the phase I), the landscape within my classroom had changed. Engagement increased and two students completed all four levels by the second day and proceeded to help others if they had questions or encountered difficulties.

On the 3rd and 4th day of the first week, many male students approached me to share that they had completed all four levels of the lite version of the game and asked whether I would be buying the full version. I decided to purchase it in the fourth week in lieu of The Health Ed Buddy app, as originally planned given its incompatibility with my teaching focus.

Throughout that first week there were only a few students who discussed the health focus of the game. Through my observations of student behaviors it appeared that the majority of the students did not realize the game's health implications, connection to the health curriculum or the content already studied this year.

There were many times throughout the week where they would ask to play another game. Subway Surfer was frequently mentioned and downloaded earlier on in the year by an unknown student that I then deleted for its lack of educational value. I frequently informed the students that they were not allowed to play any game other than Green Smoothie Lite. For most, not being permitted to play other games did not deter them. Boredom emerged from Green Smoothie as fewer students played the game and quickly passed them on to their peers.

\subsection{Week 2 - Fit Quest Lite}

In the second week of phase 1 when I announced, "Who wants to play a new game?" at least twice as many students came running up to my desk, hoping to obtain an iPod touch or iPad. Before presenting the devices to the students, I deliberately loaded the app on the device in order to circumvent any chance of students being distracted by other apps or settings.

Adam was very active in his movements, bouncing around the room, jogging while jumping and ducking simultaneously. Adam's kinesthetic actions captivated the other students in the classroom who initially didn't volunteer to play, subsequently prompting their interest in identifying what it was that he was playing.

All of the female students did not ask to play. I decided to select a female student who did not get to participate during the last 15 minutes.

During this week a few of the female students expressed that they preferred to play Green Smoothie Lite to FitQuest Lite. The males were always eager to play both games, with a penchant for FitQuest Lite. Seldom would I observe students jogging in one place. They moved around the keep their character moving in the game. During the first day one student proclaimed, "Hey look, people are exercising", reinforcing that some students were cognizant of the game's physical education components. The only hint I gave to the students was that I would pass the game to other students if existing players were found sitting and not displaying the games' required movements. Two students in the class compromised the authenticity of the game. Both of these students owned iPods at home and were familiar with how the accelerometer worked in games involving movement. These two students would sit at their chairs quietly while jerking and vibrating the iPod to simulate the running of a person.

Overall, the participating students took the game seriously performing the correct actions required by their characters, uncovering signs of potential success springing from this study. One student, who during the prior week did not make an attempt to play Green Smoothie Lite, was actively playing FitQuest Lite with the other students. This student did not receive the same amount of playtime as the other students did. However, whenever he had an opportunity to play, he would with enthusiasm. I noticed a high level of student interest in playing this game in comparison with the first weeks' game, Green Smoothie Lite.

\section{Lose It!}

When the week began with the introduction of Lose It! I clarified the game's instructions by telling students that this app was straightforward and that we would be 
measuring and recording their weight each day. Immediately, I heard a student ask aloud whether it was a game or not. When I responded by saying "No," another student quickly asked, "Can we still play the other games?" The students seemed to have made a decision that since the new app was not a game; they would not have any fun and therefore did not feel the need to participate as they did in previous weeks.

I was observing the girls while they began to eat their lunch and I could hear their initial conversation was about whether some of them should use the app or not. The conversation was more about, "Should I do it"? and "Should I get the iPod?" rather than "Should I share my weight?"

The week progressed slowly with only one more male student asking to track his weight on the app on the second day of the week. By Wednesday, there were three males and one female still tracking their weight on Lose It! That day, the lone female decided that Wednesday would be her last day to track her weight. She approached me and said,

"I don't want to play with this app anymore." The three males continued the app until the end of the week. On Friday, I showed them how their weight in all cases did not change over the span of five days. I have observed that when students enter the intermediate grades (i.e. 6, 7 or 8), any discussion about weight becomes a personal issue that few are comfortable talking about. At the grade 4 and 5 levels, when I approached this issue earlier in the year, the most frequent response I received from the students was that they had no idea what they weighed. Once we went through the stages of gathering each student's weight, the students were relatively comfortable with writing their weight down on paper and disclosing it to their classmates. Months later, only a few of these students decided to use the Lose It! app.

Lastly, since there was no character to feed, levels to finish, points to gain or rewards to win, I was concerned that students may not view this app as they did the others. Therefore there was no incentive for them to share their weight, track or even concern themselves with what happens to their weight. There was no substantial health benefit from trying out this app for a week, nor were there any broader health education lessons that emanated from the app for this particular age group. They merely saw it as an app that could record weight over a period of time. I seemed that recording one's weight over time, viewing it, setting goals, etc. was really what Lose It was meant to do, rather than to directly or indirectly teach $\mathrm{HE}$.

\section{Green Smoothie Full}

In week four I introduced the full version of Green Smoothie Lite. Once the devices were all out, immediately the eagerness of the students resurfaced as if the third week of Lose It! never existed.

To illustrate, when the second day was nearing to a close, S1 who was in the middle of an epic moment in his game play, paused the game and politely asked he if could stay a few extra minutes after the lunch bell had rung for recess to finish a difficult level. By Thursday, $\mathrm{S} 1$ and one more student completed all of the games' levels.

Midway through the week, three girls decided to challenge one another on FitQuest, week two's game. These girls continued this style of synchronized competitive gaming throughout the rest of the week. Student engagement with Green Smoothie Full lasted the entire last week of phase 1 without complaint, mention of the level of boredom or without changing the game despite the example of the girls playing FitQuest Lite in the latter part of the week.

\section{Discussion}

This study presented an innovative way of exploring how grade 4 and 5 students interact with mobile applications for the popular Apple iPad. Mobile technology lends itself to infusing pedagogical techniques in order to reach a wide array of students. Consequently, understanding how it affects student learning evolved as a natural extension of my role as my school's Technology Lead Teacher. The findings revealed the importance of selecting age appropriate apps aligned with student development; selecting apps of interest to both boys and girls, the balance between entertainment and curricular objectives; delineating mobile interaction boundaries, and the varying prior knowledge of these technological devices and applications that students enter the classroom with. The results further point to the importance of scaffolding through designated student reflection so that students are able to draw connections from these health games to the larger curricular objectives underpinning the classroom use of these apps.

Although this study found that Green Smoothie (Full Version) and FitQuest generated the most student engagement, new apps are frequently introduced serving more purposes than their predecessors. This has implications for teachers when searching for apps. Baranowski et al suggest that health games selected for the classroom may have a greater impact if the user is invested in the outcome of their actions in the game [2].

My study was not without limitations. Seldom, a few 
students were caught using the mobile devices for alternative purposes and needed redirection. Through my observations, the more comfortable the students were with the devices, the less distracted they were with exploring the device. The games additionally varied in their adherence to the Ontario Ministry of Education Health and Physical Education Curriculum, diverging in breadth and depth. Lastly, methodologically, action research provides a limited range of reality.

Future research may examine the use of native applications built into these mobile devises as mediums in teaching health education. This may reduce the time needed to sift through the numerous apps available in iTunes. Perhaps adding a component to the apps that allowed the student to respond to a question or task in order for them to move on to the next level may have provided some authenticity to the message being conveyed. Nonetheless, the potential of mobile devices to help convey health education messages to students is limited at the grade 4 and 5 level. Although, it is important to note that mobile technology can serve as a useful vehicle in teaching health education provided that there are effective tools in place (i.e. relevant apps, teacher training, technological resources) to support its usage. With the revolution in the functionality of portable networked 'smart' technologies, its potential for the classroom learning remains vast.

\section{References}

[1] Andersen, S., \& Andersen, P. (2011). Multimedia computerized smoking awareness education low-literacy Hispanics. Computers Informatics Nursing, 29, 35-42.

[2] Baranowski, T., Buday, R., Thompson, D. I., \& Baranowski, J. (2008). Playing for real: Video games and stories for health-related behavior change. American journal of preventive medicine, 34(1), 74.

[3] Barbour, M. (2012). Android Reaping Significant Gain in Canadian Marketplace. In Ipsos. Retrieved September 10, 2013, from http://www.ipsosna.com/newspolls/ pressrelease. aspx id $=5771$

[4] Boutenko, S. (2012). Green Smoothie Game Lite. In itunes Preview. Retrieved March 1, 2013, from https://itunes.apple.com/us/app/green-smoothie-game-lite/id56 $4435546 ? \mathrm{mt}=8$

[5] Consolvo, S., Everitt, K., Smith, I., \& Landay, J. A. (2006). Design requirements for technologies that encourage physical activity. In Proceedings of the SIGCHI conference on Human Factors in computing systems (pp. 457-466).

[6] Falloon, G. (2013). Young students using iPads: App design and content influences on their learning pathways. Computers \& Education, 68, 505-521.
[7] FitNow (2013). Lose It! In itunes Preview. Retrieved March 1, 2013, from https://itunes.apple.com/us/app/loseit!/id297368629? $\mathrm{mt}=8$.

[8] Free, C., Phillips, G., Watson, L., Galli, L., Felix, L., Edwards, P., \& Haines, A. (2013). The effectiveness of mobile-health technologies to improve health care service delivery processes: a systematic review and meta-analysis. PLoS medicine, 10(1).

[9] Hamm, M. P., Shulhan, J., Williams, G., Milne, A., Scott, S. D., \& Hartling, L. (2014). A systematic review of the use and effectiveness of social media in child health. $B M C$ pediatrics, 14(1), 138.

[10] JogHop. (2013). FitQuest Lite. In itunes Preview. Retrieved March 1, 2013, from

https://itunes.apple.com/us/app/fitquest-lite/id390974713?mt= 8.

[11] Kemmis, S., \& McTaggart, R. (1988). The action research planner (3rd ed.). Geelong: Deakin University Press.

[12] Kervin, L., Reid, D., Vardy, J., \& Hindle, C. (2006). A partnership for iPod pedagogy: Using the technology of millennial learners across educational contexts. In Paper published at the 23th Australasian Society for Computers in Learning in Tertiary Education Annual Conference (pp. 419-422).

[13] Lai, C. H., Yang, J. C., Chen, F. C., Ho, C. W., \& Chan, T. W. (2007). Affordances of mobile technologies for experiential learning: The interplay of technology and pedagogical practices. Journal of Computer Assisted Learning, 23(4), 326-337.

[14] Lin, J. J., Mamykina, L., Lindtner, S., Delajoux, G., \& Strub, H. B. (2006). Fish'n'Steps: Encouraging physical activity with an interactive computer game. In UbiComp 2006: Ubiquitous Computing (pp. 261-278). Springer: Berlin Heidelberg.

[15] Lynch, J., \& Redpath, T. (2012). 'Smart' technologies in early years literacy education: A meta- narrative of paradigmatic tensions in iPad use in an Australian preparatory classroom. Journal of early childhood literacy, 14: 147-174.

[16] Marcus, B. H., Owen, N., Forsyth, L. H., Cavill, N. A., \& Fridinger, F. (1998). Physical activity interventions using mass media, print media, and information technology. American journal of preventive medicine, 15(4), 362-378.

[17] Mintz, J., Branch, C., March, C., \& Lerman, S. (2012). Key factors mediating the use of a mobile technology tool designed to develop social and life skills in children with Autistic Spectrum Disorders. Computers \& Education, 58(1), 53-62.

[18] Mintz, J. (2014). The Role of User Emotional Attachment in Driving the Engagement of Children with Autism Spectrum Disorders (ASD) in Using Smartphone App Designed to 
Develop Social and Life Skill Functioning. InComputers Helping People with Special Needs (pp. 486-493). Springer International Publishing.

[19] Oakley, A. (1994). Who cares for health? Social relations, gender, and the public health. Journal of epidemiology and community health, 48(5), 427.

[20] Ostashewski, N., Reid, D. \& Ostashewski, M. (2011). The iPad as mobile teaching device: multimedia database access in a classroom context. In Proceedings of Global TIME011(pp. 49-53). AACE. Retrieved July 2, 2014 from http://www.editlib.org/p/37055.

[21] Papastergiou, M. (2009). Exploring the potential of computer and video games for health and physical education: A literature review. Computers \& Education, 53(3), 603-622.

[22] Reid, D., Kervin, L., Vardy, J., \& Hindle, C. (2006). We've got the iPods, but where do we start? The story of two grade 4 teachers. Paper published at the Mobile Learning 2006, 218-221.

[23] Selkie, E. M., Benson, M., \& Moreno, M. (2011). Adolescents' views regarding uses of social networking websites and text messaging for adolescent sexual health education. American Journal of Health Education, 42(4), 205-212.

[24] Scardamalia, M. \& Bereiter, C. (1996). Engaging Students in a Knowledge SocietyEducational Leadership, 54(3), 6-10.

[25] Thomée, S., Härenstam, A., \& Hagberg, M. (2011). Mobile phone use and stress, sleep disturbances, and symptoms of depression among young adults-a prospective cohor study. BMC public health, 11(1), 66.

[26] Vahey, P., Tatar, D., \& Roschelle, J. (2006). Using handheld technology to move between private and public in the classroom. In M. van't Hooft \& K. Swan (Eds.), Ubiquitou cmputing: Invisible technology, visible impact (187-210). Mahway, NJ: Lawrence Erilbaum Associates

[27] Wang, M., Shen, R., Novak, D., \& Pan, X. (2008). The impact of mobile learning on students' learning behaviours and performance: Report from a large blended classroom. British Journal of Educational Technology, 40(4), 673-695.

[28] Wenglinsky, H. (1998). Does it compute? The relationship between educational technology and student achievement in mathematics. Princeton, NJ: Educational Testing Service. 